RAFAEL HERLING LAMBERTUCCI

\title{
CONTROLE DA PRODUÇÃO MUSCULAR DE ESPÉCIES REATIVAS E CITOCINAS POR ÁCIDO PALMÍTICO E ELETROESTIMULAÇÃO: POSSÍVEIS IMPLICAÇÕES NO ENVELHECIMENTO
}

Tese apresentada ao Instituto de Ciências Biomédicas da Universidade de São Paulo, para a obtenção do Título de Doutor em Ciências (Fisiologia Humana). 
RAFAEL HERLING LAMBERTUCCI

\title{
CONTROLE DA PRODUÇÃO MUSCULAR DE ESPÉCIES REATIVAS E CITOCINAS POR ÁCIDO PALMÍTICO E ELETROESTIMULAÇÃO: POSSÍVEIS IMPLICAÇÕES NO ENVELHECIMENTO
}

\author{
Tese apresentada ao Instituto de \\ Ciências Biomédicas da Universidade \\ de São Paulo, para a obtenção do \\ Título de Doutor em Ciências. \\ Área de concentração: Fisiologia \\ Humana \\ Orientadora: Profa. Dra. Tania \\ Cristina Pithon-Curi
}




\section{RESUMO}

Lambertucci RH. Controle da Produção Muscular de Espécies Reativas e Citocinas por Ácido Palmítico e Eletroestimulação: Possíveis Implicações no Envelhecimento [Tese - Doutorado em Ciências]. São Paulo: Instituto de Ciências Biomédicas da Universidade de São Paulo; 2009.

Espécies reativas de oxigênio e nitrogênio controlam várias funções celulares, no entanto, quantidades excessivas destas espécies causam disfunções. Com o envelhecimento, há aumento da produção destas espécies, e de citocinas, que também exercem efeitos deletérios na musculatura esquelética, e da concentração plasmática de ácidos graxos. Contudo, a possível rassociação entre o aumento da produção de espécies reativas e de citocinas pelo músculo esquelético e da concentração plasmática de ácidos graxos não foi ainda investigada. O presente estudo teve como objetivo avaliar a modulação da produção muscular de espécies reativas de oxigênio e nitrogênio e de citocinas pelo ácido palmítico e pela eletroestimulação moderada. O ácido palmítico aumentou a produção de superóxido (via mitocôndria e NADPH oxidase), óxido nítrico (via iNOS) e citocinas (IL-6 e CINC2), além de ativar o NF-kB. A eletroestimulação aumentou a produção de superóxido (via mitocôndria e sistema xantina-xantina oxidase), óxido nítrico (via iNOS) e ativou o NF-kB. Não foi observado aumento de citocinas no protocolo de eletroestimulação. O ácido palmítico, portanto, controla a produção de espécies reativas e citocinas pelo músculo. A eletroestimulação, também aumenta a produção destas espécies. Assim, o estresse oxidativo muscular é controlado pela atividade contrátil e as concentrações de ácidos graxos plasmáticos.

Palavras-chave: Espécies reativas; Citocinas; Ácido palmítico; Envelhecimento; Eletroestimulação. 


\begin{abstract}
Lambertucci RH. Control of Muscular Production of Reactive Species and Cytokines by Palmitic Acid and Eletrical Estimulation: Possible Implications in Aging [Doctor thesis - Scienses]. São Paulo: Instituto de Ciências Biomédicas da Universidade de São Paulo; 2009.

Reactive oxygen and nitrogen species play a key role in several cell functions, however, high concentrations of these species cause cell dysfunction. High production of reactive species, and cytokines, which also induce skeletal muscle injury, and an increase of plasma concentration of fatty acids are observed in aging. However, an association between the augment in the production of reactive species and cytokines by skeletal muscle and of plasma fatty acid concentrations was not investigated yet. The aim of the present study was to evaluate the modulation of production of reactive oxygen and nitrogen species and of cytokines by palmitic acid and electrical stimulation muscle contraction. Palmitic acid increased the production of superoxide (through mitochondria and NADPH oxidase), nitric oxide (by iNOS), and citokynes (IL-6 and CINC-2), and induced NF-KB activation. The electrical stimulation-muscle contraction increased the production of superoxide (through mitochondria and xanthine-xanthine oxidase system), nitric oxide (by iNOS), and induced NF-KB activation. There was no change in the production of cytokines in the electrical stimulation protocol. In conclusion, palmitic acid raised the production of reactive oxygen and nitrogen species and cytokines by skeletal muscle. Electrical stimulation-muscle contraction also increased the production of these reactive species. Therefore, muscle oxidative stress is controlled by the muscle contractile activity and plasma fatty acid levels.
\end{abstract}

Keywords: Reactice species; Cytokines; Palmitic acid; Aging; Electric stimulation. 


\section{INTRODUÇÃO}

Há cerca de 2,4 bilhões de anos aconteceu um grande marco na história da evolução biológica, surgiram os primeiros organismos aeróbios, as algas marinhas. A utilização do oxigênio $\left(\mathrm{O}_{2}\right)$ como aceptor final de elétrons no processo de fosforilação oxidativa aumentou consideravelmente a eficiência na produção de energia a partir dos alimentos (Ji, 1999). Entretanto, apesar do papel fundamental do oxigênio no processo de fosforilação oxidativa, o que permite ao nosso organismo utilizar a energia proveniente de nutrientes como carboidratos, lipídios e proteínas com maior eficiência, uma pequena fração do seu consumo mitocondrial é transformada em espécies reativas de oxigênio (EROs) (Chance, Sies e Boveris, 1979; Ji, 1999). A formação dessas espécies foi inicialmente desmonstrada com o clássico estudo de Mccord e Fridovich (1968), monstrando a formação do radical superóxido $\left(\mathrm{O}_{2}{ }^{-*}\right)$ pela enzima xantina oxidase. Anos depois, estes mesmos autores demonstraram, ainda, que as EROs são também causadoras de danos oxidativos aos tecidos em organismos vivos (Mccord, 1974).

É consenso na literatura que um nível ideal de EROs é essencial para a sobrevivência celular. Excesso de EROs pode causar disfunções fisiológicas devido aos danos celulares e moleculares, como também pode sinalizar a apoptose. Entretanto, quantidades pequenas de EROs pode induzir diminuição da proliferação de determinados leucócitos e redução da função imune (Finkel e Holbrook, 2000; Ji, Gomez-Cabrera e Vina, 2006).

$\mathrm{O}$ aumento de danos moleculares induzidos por EROs podem ocasionar alterações na expressão gênica, instabilidade genômica, mutações, heterogeneidade celular, diminuição da proliferação celular e sinalização intracelular, morte celular, desorganização tecidual, disfunção de órgãos, entre outros (Rattan, 2006).

Carl Wilhem Scheele foi o primeiro pesquisador a descrever os efeitos negativos do oxigênio em seres vivos, isso ainda no século XVIII. Entretanto, uma explicação científica desses efeitos danosos demorou cerca de 200 anos para ser publicada. Atualmente, sabe-se que os efeitos prejudiciais de altas tensões de oxigênio em sistemas biológicos devem-se à geração de espécies reativas de oxigênio (EROs) (Sanz, Pamplona e Barja, 2006). 
Os termos radicais livres ( $R L$ ) e espécies reativas de oxigênio (EROs) tem sido comumente utilizados indistintamente. Contudo, há diferenças entre tais terminologias. As EROs, segundo Halliwell e Gutteridge (1999), é um termo coletivo utilizado pelos pesquisadores que inclui as espécies derivadas do oxigênio, tanto radicalares como não radicalares. As radicalares são a que chamamos de radicais livres, e são caracterizadas por possuírem elétrons desemparelhados em seu último orbital, acarretando em alta reatividade. Estes incluem principalmente: ânion superóxido $\left(\mathrm{O}_{2}{ }^{-}\right)$, radicais hidroxil $\left({ }^{\circ} \mathrm{OH}\right)$, peroxil $\left(\mathrm{RO}_{2}{ }^{\circ}\right)$, alcoxil $\left(\mathrm{RO}^{\circ}\right)$ e hidroperoxil $\left(\mathrm{HO}_{2}{ }^{\circ}\right)$. Já as não radicalares, caracterizadas por possuírem elétrons pareados, são formadas principalmente por peróxido de hidrogênio $\left(\mathrm{H}_{2} \mathrm{O}_{2}\right)$, ácido hipoclorídrico $(\mathrm{HOCl})$, ozônio $\left(\mathrm{O}_{3}\right)$ e oxigênio singlete $\left({ }^{1} \mathrm{O}_{2}\right)$.

Para que não ocorra acúmulo de EROs, e com isso um aumento de danos oxidativos às células, há no organismo sistemas antioxidantes, que protegem direta ou indiretamente todas as células, e podem ser divididos em sistema antioxidante não enzimático e enzimático (Rodriguez, et al., 2004).

Os antioxidantes não enzimáticos são compostos principalmente por vitaminas C e E, $\beta$-caroteno, coenzima Q-10, glutationa reduzida $(\mathrm{GSH})$, cisteína, fitoestrógenos e melatonina. Já entre os enzimáticos encontramos principalmente as enzimas superóxido dismutases (SOD), catalase (CAT), glutationa peroxidase (GPX) e glutationa redutase (GR) (Halliwell e Gutteridge, 1999; Wei e Lee, 2002).

A SOD é uma enzima que dismuta o radical superóxido convertendo-o em peróxido de hidrogênio. Em humanos foram identificados 3 tipos de SOD: (1) uma citosólica, que contém o íon cobre no seu sítio ativo, o qual participa da reação, e contém também o íon zinco, que tem função de estabilização molecular (Cu,ZnSOD); (2) uma mitocondrial que possui o íon manganês em seu sítio ativo, que participa na reação de dismutação (Mn-SOD); (3) uma extracelular, que é na verdade uma Cu,Zn-SOD encontrada fora do meio intracelular (EC-SOD) (Halliwell e Gutteridge, 1999). As esquematizações da reação de dismutação do superóxido realizadas pelas enzimas $\mathrm{Cu}, \mathrm{Zn}-\mathrm{SOD}$ e $\mathrm{Mn}-\mathrm{SOD}$ podem ser observadas nas figuras 1 e 2. 


$$
\begin{aligned}
& \text { Enzima-Cu }{ }^{2+}+\mathrm{O}_{2} \bullet-\text { Enzima-Cu}^{+}+\mathrm{O}_{2} \\
& \text { Enzima-Cu}{ }^{+}+\mathrm{O}_{2}{ }^{-}+2 \mathrm{H}^{+} \longrightarrow \text { Enzima-Cu}{ }^{2+}+\mathrm{H}_{2} \mathrm{O}_{2} \\
& \mathrm{O}_{2}^{\cdot-}+\mathrm{O}_{2}^{\bullet-}+2 \mathrm{H}^{+} \longrightarrow \mathrm{H}_{2} \mathrm{O}_{2}+\mathrm{O}_{2}
\end{aligned}
$$

Figura 1 - Reação de dismutação do ânion superóxido realizado pela enzima Cu,Zn-SOD. Adaptado de Halliwell e Gutteridge (1999).

$$
\begin{aligned}
& \text { Enzima-Mn }{ }^{3+}+\mathrm{O}_{2}{ }^{--} \longrightarrow \text { Enzima-Mn }{ }^{2+}+\mathrm{O}_{2} \\
& \text { Enzima-Mn }{ }^{2+}+\mathrm{O}_{2}{ }^{--}+2 \mathrm{H}^{+} \longrightarrow \text { Enzima-Mn }{ }^{3+}+\mathrm{H}_{2} \mathrm{O}_{2} \\
& \mathrm{O}_{2}^{\cdot-}+\mathrm{O}_{2}^{\cdot-}+2 \mathrm{H}^{+} \longrightarrow \mathrm{H}_{2} \mathrm{O}_{2}+\mathrm{O}_{2}
\end{aligned}
$$

Figura 2 - Reação de dismutação do ânion superóxido realizado pela enzima Mn-SOD. Adaptado de Halliwell e Gutteridge (1999).

A catalase (CAT) é uma enzima tetramérica, formada por 4 subunidades idênticas de 60 kDa. Ela é conhecida como uma das enzimas mais eficientes, não podendo ser saturada pelo peróxido de hidrogênio em qualquer concentração fisiológica (Lledias, Rangel e Hansberg, 1998). A CAT está presente principalmente nos peroxissomos, e possui o íon ferro no seu sítio ativo, o qual reage com o peróxido de hidrogênio formando água e oxigênio. Entretanto, ela não é essencial para algumas células em condições basais, tendo maior importância na aquisição da tolerância ao estresse oxidativo (Rodriguez, et al., 2004). Observa-se a seguir a reação da CAT com o peróxido de hidrogênio, convertendo-o em água e oxigênio (Figura 3). 


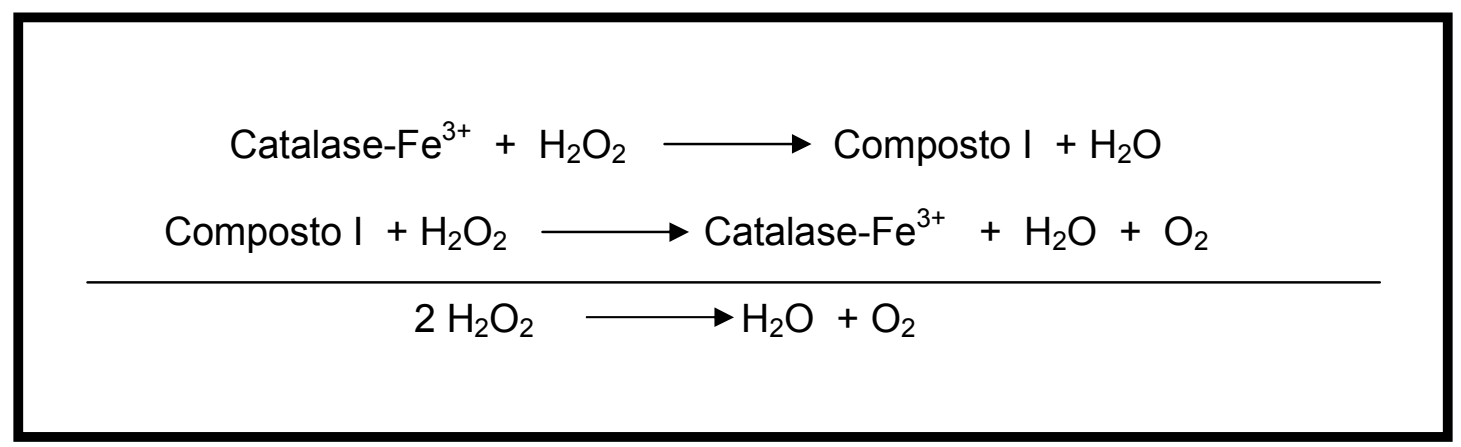

Figura 3 - Mecanismo de reação da enzima catalase, convertendo o peróxido de hidrogênio em água e oxigênio. Adaptado de Halliwell e Gutteridge (1999).

A glutationa peroxidase (GPX) é a principal fonte de proteção celular na presença de baixa concentração de peróxido de hidrogênio, e também é responsável por catalisar a redução de uma variedade de hidroperóxidos $(\mathrm{ROOH} e$ $\mathrm{H}_{2} \mathrm{O}_{2}$ ) utilizando glutationa reduzida (GSH), formando água e glutationa oxidada (GSSG). Com isso torna-se de grande importância "reciclar" a GSH a partir da GSSG, e esse processo é realizado pela glutationa redutase (GR) (Halliwell e Gutteridge, 1999). Seguem abaixo as reações realizadas pela GPX utilizando a GSH, como também a reação da GR, reciclando a GSH (Figura 4).

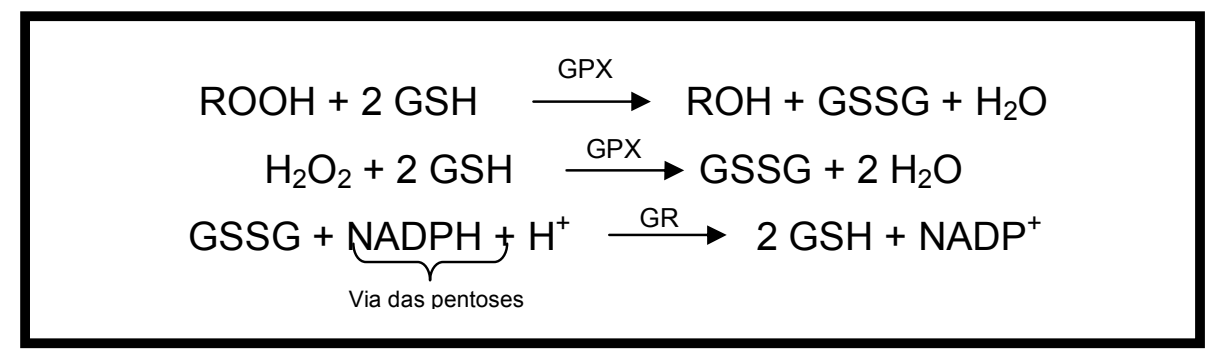

Figura 4 - Mecanismo de reação das enzimas glutationa peroxidase e redutase. Adaptado de Halliwell e Gutteridge (1999).

A GSH possui papel multifuncional na proteção dos tecidos contra danos oxidativos. Primeiramente ela reduz o peróxido de hidrogênio $\left(\mathrm{H}_{2} \mathrm{O}_{2}\right)$ e peróxidos orgânicos através da reação catalisada pela glutationa peroxidase; segundo, age eliminando os oxigênios singlete $\left({ }^{1} \mathrm{O}_{2}\right)$ e a hidroxila $\left(\mathrm{OH}^{\bullet-}\right)$; e finalmente, é utilizada na redução de radicais tocoferóis tanto direta como indiretamente, prevenindo assim a peroxidação lipídica (Ji, 1995).

O peróxido de hidrogênio, apesar de não ser classificado como radical livre, e por isso não apresentar alta reatividade, se não decomposto pela CAT ou pela GPX, 
pode ser convertido em uma ERO altamente reativa, a hidroxila $\left({ }^{\circ} \mathrm{OH}\right)$, através da reação de Fenton que utiliza metais de transição como o ferro em seu estado $2\left(\mathrm{Fe}^{2+}\right.$ $+\mathrm{H}_{2} \mathrm{O}_{2} \rightarrow \mathrm{Fe}^{3+}+\mathrm{OH}^{-}+{ }^{\circ} \mathrm{OH}$ ) (Miwa e Brand, 2003). Esse processo pode ser facilitado quando há acúmulo de ânion superóxido, pois o mesmo é capaz de reduzir o $\mathrm{Fe}^{3+}$ em Fe ${ }^{2+}$ (Kang e Hamasaki, 2003).

A respiração mitocondrial utiliza aproximadamente $90 \%$ do oxigênio consumido pelas células, e cerca de $1 \%$ a $5 \%$ deste oxigênio consumido é convertido em EROs, sendo portanto, a cadeia de transporte de elétrons o principal sítio produtor de EROs devido ao vazamento de elétrons por essa cadeia (Papa, 1996; Reid e Durham, 2002; Wei e Lee, 2002).

A mitocôndria é uma organela de dupla membrana considerada essencial para vida de todos os eucariotos e é responsável pela produção da maior parte do ATP celular através da fosforilação oxidativa na cadeia de transporte de elétrons (Bonawitz e Shadel, 2007).

A cadeia de transporte de elétrons (CTE) mitocondrial está localizada na membrana interna mitocondrial, e tem papel fundamental na produção de energia (ATP) em organismos aeróbios. Esta é formada por cinco complexos protéicos: $\mathrm{NADH}$ desidrogenase (complexo I), succinato desidrogenase (complexo II), complexo citocromo bc1 (complexo III), citocromo c oxidase (COX) (complexo IV), e ATP sintase (complexo V) (Mandavilli, Santos e Van Houten, 2002). Os elétrons do $\mathrm{NADH}$ (forma reduzida de nicotinamina adenina dinucleotídeo) e $\mathrm{FADH}_{2}$ (forma reduzida de flavina adenina dinucleotídeo), produzidos durantes vários processos metabólicos, passam pela CTE, através dos complexos I e II, respectivamente, os quais criam uma eletronegatividade fazendo com que os complexos I, III e IV utilizem a energia derivada para bombear prótons através da membrana mitocondrial interna, criando um gradiente eletroquímico. Finalmente esse potencial é utilizado para a formação de ATP através do complexo V (Figueiredo, et al., 2008). Normalmente cada molécula de oxigênio no complexo IV recebe quatro elétrons, formando duas moléculas de água, havendo também, liberação de energia. Entretanto, os elétrons podem reagir prematuramente com o oxigênio em complexos anteriores levando à formação do radical superóxido. Sabidamente os dois maiores sítios produtores de EROs na mitocôndria são os complexos I e III, onde o primeiro contribui com o escape de elétrons na matriz mitocondrial, e o complexo 3 na matriz e no citoplasma. O radical superóxido então formado, caso não seja eficientemente 
anulado pelo sistema antioxidante, pode ainda ser convertido em peróxido de hidrogênio e radical hidroxil (Finkel e Holbrook, 2000; Balaban, Nemoto e Finkel, 2005). A figura 5 esquematiza a produção de superóxido pela mitocôndria, onde há produção pelo complexo I, liberando superóxido para a matriz mitocondrial, e pelo complexo III, o qual libera essa ERO tanto para a matriz como para citoplasma. O papel das enzimas antioxidantes na eliminação das EROs produzidas na mitocôndria também está ilustrado (Figura 5).

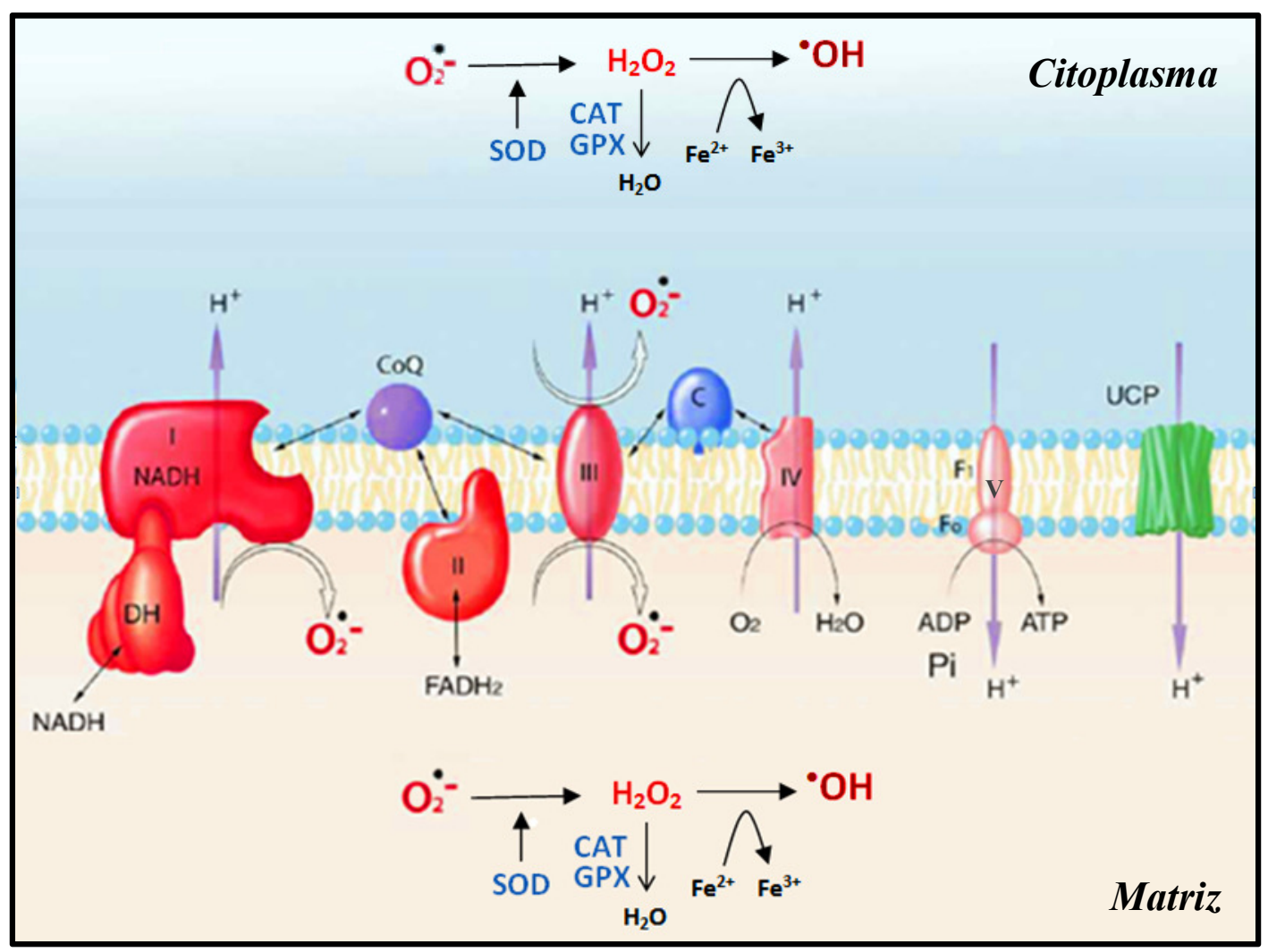

Figura 5 - Esquematização da produção de espécies reativas de oxigênio pela cadeia de transporte de elétrons mitocondrial, participação do sistema antioxidante enzimático, e da proteína desacopladora (UCP). Adaptado de Kang e Hamasaki (2003) e Bonawitz e Shadel (2007).

Como a mitocôndria é o principal sítio produtor de EROs, e o tecido muscular esquelético é caracterizado por ser um tecido que possui muitas mitocôndrias, este acaba sendo o principal alvo destas espécies. Além disso, o músculo esquelético apesar de apresentar uma alta produção de EROs através da cadeia de transporte de elétrons (Banerjee, et al., 2003; Balaban, Nemoto e Finkel, 2005), também possui outras duas importantes fontes geradoras destas espécies, os sistemas xantina-xantina oxidase e NADPH-oxidase (Lagranha, et al., 2005). 
O tecido muscular esquelético tem funções importantes no organismo tais como locomoção, produção de calor, respiração, sustentação postural, entre outros. Com isso a preservação de sua massa é fundamental (Carmeli, et al., 2004; Guttridge, 2004). Uma diminuição significativa da massa muscular pode ser observada pelo desuso, desnervação, imobilização, sepse, neoplasia, diabetes, AIDS e envelhecimento (Solomon e Bouloux, 2006).

Além das EROs o músculo esquelético também pode sofrer danos pela produção de outras espécies reativas, as de nitrogênio (ERNs), tendo o óxido nítrico (NO) como principal espécie nesse tecido. O NO possui papel fisiológico fundamental por agir como um modulador endógeno na função do músculo esquelético, regulando vários processos como transporte de glicose, respiração mitocondrial, fluxo sangüíneo e geração de força (Pattwell, et al., 2004; Jackson, Pye e Palomero, 2007), além de controlar a produção de diversos hormônios, dentre eles a vasopressina, somatostatina, ocitocina, hormônio do crescimento e hormônio luteinizante (Mccann, et al., 2005).

O NO é sintetizado a partir da L-arginina pela enzima NO sintase (NOS) usando NADPH e oxigênio como substratos (Marletta, Hurshman e Rusche, 1998). A enzima NOS possui três isoformas: a neuronal (nNOS ou NOS I), a induzível (iNOS ou NOS II) e a endotelial (eNOS ou NOS III). No músculo esquelético, a eNOS está localizada na mitocôndria e a nNOS associada ao complexo da distrofina no sarcolema. A iNOS é expressa em níveis muito baixos mas pode aumentar significativamente em certas condições (Vassilakopoulos, et al., 2007). Na verdade, as fontes celulares de NO no músculo esquelético continuam incertas (Silveira, et al., 2006; Jackson, Pye e Palomero, 2007).

Recentemente foi demonstrado que a enzima NOS possui uma isoforma que encontra-se associada à membrana interna mitocondrial (mtNOS). Ela aparenta ser idêntica à isoforma neuronal (nNOS), e pode causar danos mitocondriais e também para outros compartimentos celulares podendo induzir a morte celular (Giulivi, Poderoso e Boveris, 1998; Navarro, et al., 2002).

A meia-vida do NO em solução é de aproximadamente 5-10 segundos, sendo esse um gás solúvel em meio líquido, sendo portanto, capaz de se difundir para células vizinhas. O NO é suficientemente tóxico para causar danos por sua capacidade de difusão e também por se combinar com o superóxido, formando o peroxinitrito, um radical muito mais potente que o NO e o superóxido. Essa reação é 
aproximadamente três vezes mais rápida do que a dismutação do superóxido pela superóxido dismutase, indicando que esta formação é favorecida quando estão presentes o superóxido e o óxido nítrico (Patwell, et al., 2004; Mccann, et al., 2005).

O NO pode também exercer efeito tóxico na célula, pois ele pode se combinar a grupos heme, de várias enzimas, inativando-as e bloqueando a respiração celular levando à morte celular. Na verdade o aumento exacerbado na produção de NO está relacionado com o desenvolvimento de diversas patologias como Parkinson, Alzheimer e Huntington (Mccann, et al., 2005).

Com isso, é evidente que tanto as EROs quanto as ERNs quando não eliminadas adequadamente, podem acarretar diversos danos ao tecido muscular esquelético, o qual deve se regenerar para continuar a exercer suas funções plenamente (Carmeli, et al., 2004; Guttridge, 2004).

A habilidade do músculo esquelético de se regenerar ou hipertrofiar é principalmente dependente de sua população de células progenitoras denominadas células satélites. Estas células estão presentes entre a membrana muscular (sarcolema) de fibras maduras e sua lamina basal (Renault, et al., 2002).

Em células musculares maduras, as células satélites encontram-se em um estado quiescente, mas podem ser ativadas por diversos estímulos, como alongamento, desnervação e dano muscular. Após ativação, estas células se dividem e se diferenciam para reparar as fibras lesionadas (Bortoli, et al., 2003). Quando os danos são mínimos, as células satélites se fundem às fibras já existentes, e quando há uma lesão massiva, se fundem uma nas outras formando uma nova fibra muscular (Shefer, et al., 2006).

A proliferação e a diferenciação de células satélites é dependente de um grupo de genes pertencentes à família de fatores de regulação miogênica (MRFs myogenic regulatory factors). Esses genes são MyoD (Myf-1), Myf-5, miogenina (Myf-4) e MRF4 (Myf-6/Herculina). Os genes MyoD e Myf-5, conhecidos como MRFs primários, são necessários para o processo de proliferação, e os genes miogenina e MRF4, conhecidos como MRFs secundários, são necessários para o processo de diferenciação (Sabourin e Rudnicki, 2000; Yablonka-Reuveni, et al., 2008). Na figura a seguir (Figura 6) está ilustrado o processo de proliferação e diferenciação de células satélites em miotubos, bem como a indicação da participação dos principais genes envolvidos nesse processo. 


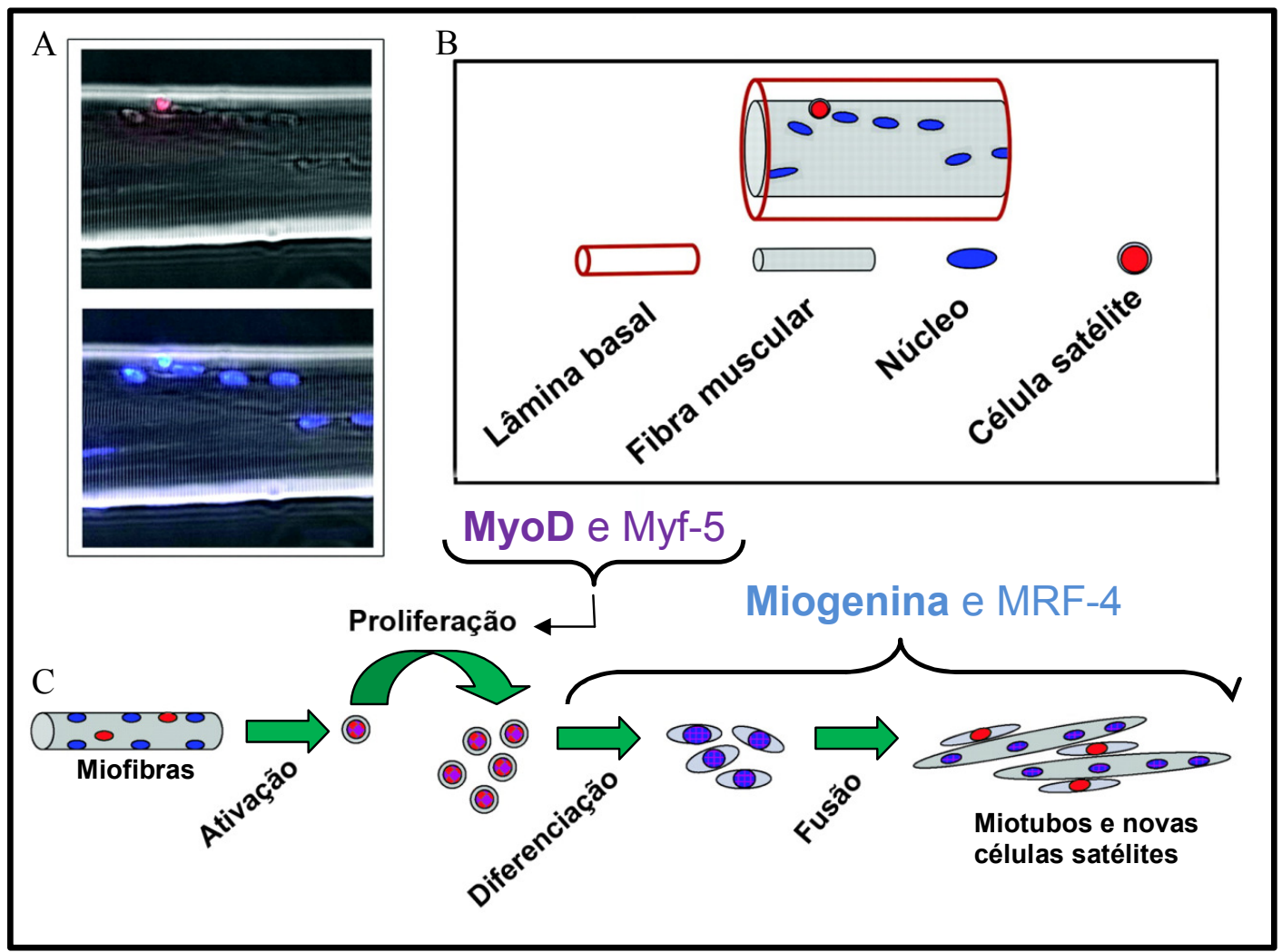

Figura 6 - (A) Imunomarcação de uma fibra muscular isolada do músculo extensor longo dos dedos (EDL) de um camundongo adulto; (B) llustração da fibra muscular apresentada no painel A; (C) Modelo de ativação, proliferação e diferenciação de células satélites em função da expressão de genes de regulação miogênica (MyoD, Myf-5, miogenina e MRF-4). Adaptado de Sabourin e Rudnicki (2000) e Yablonka-Reuveni, et al. (2008).

Após o dano muscular inicia-se uma rápida e seqüencial invasão de células inflamatórias que pode persistir por dias a semanas, até que ocorra regeneração completa do tecido lesionado (Tidball, 2005).

Os neutrófilos migram para o tecido muscular após a lesão. Essa invasão inicia-se em um período de 1 hora e pode durar até 5 dias (Fielding, et al., 1993). Achados recentes tem demonstrado que os neutrófilos são capazes de lisar diretamente as membranas das células musculares através da produção de superóxido (Tidball, 2005).

Há também a migração de macrófagos, a qual possui importante papel no processo de reparo de danos musculares (Tidball, 2005). De acordo com esse pesquisador, os macrófagos auxiliam no processo de regeneração removendo os debris celulares gerados após uma lesão. Além disso, há aumento na produção de 
citocinas proinflamatórias pelos leucócitos, como também pelo próprio músculo esquelético (Pedersen, et al., 2007).

Algumas citocinas possuem também um efeito negativo direto no músculo esquelético, levando a uma redução de sua massa e conseqüentemente de sua força (Visser, et al., 2002). Haddad, et al. (2005), demonstraram uma diminuição de $17 \%$ de proteínas miofibrilares 14 dias após a infusão de IL-6 em camundongos. Estas podem levar a redução no processo de síntese protéica muscular por prejudicar a via de síntese mediada por IGF-1 (Edstrom e Ulfhake, 2005).

De acordo com Pedersen, et al. (2007), as citocinas e outros peptídeos produzidos, expressos e liberados pelo músculo esquelético, e que exercem efeitos parácrino e endócrino são classificadas como miocinas. A lista de miocinas vem crescendo gradativamente, e atualmente essas incluem TNF- $\alpha$ (fator de necrose tumoral- $\alpha$ ), IL-1 $\beta$ (interleucina 1- $\beta$ ), IL-1Ra (receptor antagonista de interleucina 1), IL-6 (interleucina-6), IL-8 (interleucina-8), IL-10 (interleucina-10), IL-15 (interleucina-15) e MCP-1 (proteína quimiotática de monócito) (Wei, et al., 2008).

A IL-6 foi a primeira citocina a ser caracterizada no tecido muscular esquelético dando origem ao termo miocinas (Pedersen, et al., 2007). É uma citocina importante que modula a resposta imune tendo efeitos pro e antiinflamatórios. Ela é produzida por vários tecidos, e tem sua produção no músculo aumentada em resposta ao exercício intenso, podendo ter papel importante na manutenção da homeostase da glicose durante e após o exercício (Pedersen, Steensberg e Schjerling, 2001; Lopez-Soriano, et al., 2006). De acordo com Pedersen (2007), a IL6 é geralmente classificada como sendo uma citocina proinflamatória, entretanto, dados atuais sugerem que esta citocina possui papel antiinflamatório regulando a resposta à fase aguda do processo inflamatório. Porém, níveis elevados de forma crônica exercem efeitos proinflamatórios estando associados a disfunções do metabolismo e caquexia.

A IL-8 foi caracterizada em 1987 por três grupos de pesquisadores distintos como sendo um fator ativador de neutrófilos (Pedersen, et al., 2007). Trata-se de uma citocina de baixo peso molecular, também classificada como uma quimiocina, que possui papel importante no processo inflamatório e na patogênese vascular por regular a migração, infiltração e ativação de leucócitos (Wei, et al., 2008). A produção dessa citocina aumenta com o exercício intenso (Akerstrom, et al., 2005). Entretanto, sua função no tecido muscular esquelético ainda não foi estabelecida 
(Wei, et al., 2008). É sugerido que sua função é de quimioatração de neutrófilos e macrófagos ao músculo em resposta ao exercício, além de estimular a angiogênese (Pedersen, et al., 2007). Em ratos não há a presença de IL-8, no entanto, existe uma família de citocinas que apresentam funções similares a esta, o grupo das CINC (Nakagawa, et al., 1994).

O TNF- $\alpha$ é uma citocina que induz várias respostas celulares como apoptose, proliferação e produção de moléculas inflamatórias. É produzido pelo músculo esquelético e por leucócitos (Pedersen, et al., 2007).

A IL-1 $\beta$ é uma citocina proinflamatória associada à destruição de células beta pancreáticas levando ao desenvolvimento de diabetes mellitus tipo 1. Já o IL-1Ra é uma citocina antiinflamatória que inibe a ação proinflamatória mediada pela IL-1 (Wei, et al., 2008).

A IL-10 é uma citocina antiinflamatória clássica que parece exercer efeitos benéficos antiinflamatórios no músculo esquelético por ter sua concentração aumentada no plasma mediada pelo exercício físico intenso (Pedersen, et al., 2007).

Em suma, todos os processos citados anteriormente neste estudo, como o excesso de EROs, de ERNs e citocinas pró-inflamatórias, são suficientemente capazes de gerar lesões musculares. Além disso, há uma condição onde estes três processos podem agir concomitantemente, agravando os danos causados por esses elementos ao tecido muscular, trata-se do envelhecimento.

O envelhecimento é um processo progressivo, endógeno e irreversível para os indivíduos (Sanz, Pamplona e Barja, 2006), que leva ao declínio das funções corporais, aumento da suscetibilidade à doenças e conseqüentemente, o risco de morte (Figueiredo, et al., 2008).

A progressão do envelhecimento é variável entre organismos de uma mesma espécie, dentro de órgão e tecidos de um mesmo organismo, em tipos celulares de um tecido, em compartimento subcelulares de um tipo celular, e em macromoléculas de uma célula (Rattan, 2006).

O processo de envelhecimento é responsável por alterações em todos os sistemas do organismo, contudo, são as perdas ocorridas no sistema muscular esquelético que causam o maior impacto na qualidade de vida dos idosos. Conforme o ser humano envelhece a massa muscular diminui tornando-se frágil, levando à instabilidade, perda da capacidade funcional e perda parcial ou total da independência, dificuldade de realizar as tarefas do dia-a-dia e, principalmente, 
aumentam os riscos de quedas, que são uma das principais causas de acidentes na terceira idade (Mcardle, Vasilaki e Jackson, 2002; Fitts, 2003).

De acordo com Thomas (2007), há três categorias primárias que levam à perda de massa muscular: 1) desnutrição; 2) caquexia; 3) sarcopenia. A desnutrição, dada por uma falta de alimentação suficiente, está relacionada a um balanço protéico/energético negativo, o que leva a uma perda do tecido adiposo e muscular. Esse processo pode ser completamente ou parcialmente revertido através da reposição de nutrientes. A caquexia (kak - ruim, hexis - condição), está relacionada a um estado debilitante severo induzido por alguma patologia como câncer ou imunodeficiência, podendo haver perda de até $80 \%$ da massa muscular. Já a sarcopenia pode ser definida simplesmente como uma perda de massa muscular relacionada à idade.

A perda de massa muscular entre os 20 e 90 anos é de aproximadamente $50 \%$, sendo a taxa de perda cerca de 1-2\% por ano após os 50 anos de idade. Esta relaciona-se a redução de força (dinâmica, estática e isocinética) e do consumo máximo de oxigênio $\left(\mathrm{VO}_{2 \max }\right)$ de 3-8\% por década, a partir dos 30 anos de idade (Thomas, 2007). Uma perda de $10 \%$ ou mais do peso corporal total após os 50 anos de idade está associada a um aumento de $60 \%$ de mortalidade quando comparado com pessoas com peso estável (Thomas, 2005).

$\mathrm{Na}$ tentativa de entender completamente o envelhecimento, inúmeras teorias sobre esse processo foram criadas (Medvedev, 1990). Esse autor buscou realizar uma classificação das diversas teorias do processo de envelhecimento, tendo relacionado mais de 300 delas, como por exemplo, a teoria neuroendócrina, teoria de senescência replicativa, teoria da glândula pineal, teoria imunológica, teoria do erro protéico, entre outras. Entretanto, atualmente, o aumento do estresse oxidativo é a causa mais aceita para o processo de envelhecimento (Balaban, Nemoto e Finkel, 2005).

Existem evidências que sugerem que a formação de EROs pode ser um dos fatores determinantes do envelhecimento, dentre elas: (1) EROs são constantemente produzidas pela atividade celular normal; (2) EROs são moléculas altamente reativas que podem gerar diversos danos, podendo assim explicar as diversas alterações relacionadas com o envelhecimento; (3) manipulação de antioxidantes apresentam grande efeito na longevidade; (4) restrição calórica causa redução da produção de EROs acompanhada pelo aumento da expressão de 
enzimas antioxidantes, tendo com isso grande efeito na longevidade (Dufour e Larsson, 2004).

Entretanto, com o processo de envelhecimento, ocorre um desequilíbrio entre a produção de EROs e sua neutralização (estresse oxidativo), o que pode acarretar em vários danos oxidativos a diversos tecidos (Wei e Lee, 2002; Figueiredo, et al., 2008).

Vários autores tem investigado o papel das EROs no processo de envelhecimento em diferentes organismos. Em fibroblastos Serra, et al. (2003), demonstraram que o aumento na concentração da enzima superóxido dismutase (SOD) prolongou o tempo de vida dessas células. Já Blander, et al. (2003), demonstraram que o nocaute do gene da SOD usando a técnica de RNA de interferência (RNAi), induziu a senescência dos fibroblastos. Resultados semelhantes onde novamente foram manipulados o conteúdo de proteínas anti- e/ou pró-oxidantes em outros organismos (minhocas, moscas, camundongos, entre outros) demonstraram resultados que também evidenciam a função das EROs no processo de envelhecimento (Balaban, Nemoto e Finkel, 2005).

A primeira teoria relacionando o processo de envelhecimento com a produção excessiva de EROs foi a proposta por Harman (1956). Este propôs que com o envelhecimento ocorre aumento na produção de radicais livres, que está diretamente associado, entre outros fatores, com a peroxidação lipídica, oxidação de algumas enzimas, oxidação e degradação protéica e até mesmo danos ao DNA, que desencadeiam alterações lentas e progressivas nos tecidos e no código genético. Segundo esse autor, o aumentado de radicais livres com o envelhecimento, ocorre devido a alterações na cadeia de transporte de elétrons e dos mecanismos celulares de defesa antioxidante.

Alguns anos depois a teoria de Harman foi reescrita pelo próprio autor, e surgiu a hipótese de que a mitocôndria é o principal alvo do ataque de espécies reativas de oxigênio (EROs), o que leva ao envelhecimento, criando assim a "teoria dos radicais livres do envelhecimento" (Harman, 1972, 1981).

As afirmações da teoria de Harman, de que a mitocôndria é o principal alvo de ataque de EROs, foram pela primeira vez confirmadas em trabalho realizado por Miquel, et al. (1980), onde demonstraram que os danos causados ao DNA mitocondrial (mtDNA) em tecido de animais aumenta durante o envelhecimento. $O$ 
mesmo autor, anos depois, obteve resultados que continuavam suportando as afirmações de Harman (Miquel, 1991).

Com bases nas afirmações de que a mitocôndria é o principal alvo de ataque das EROs, Linnane, et al. (1989), criaram a "teoria mitocondrial do envelhecimento", na qual é evidenciado que o aumento da produção de EROs durante esse processo ocasiona um acúmulo de mutações no mtDNA, que é o principal fator responsável para o envelhecimento, assim como para o desenvolvimento de doenças degenerativas (Wei e Lee, 2002).

A mitocôndria possui seu próprio genoma (DNA mitocondrial - mtDNA), o qual codifica diversas subunidades importantes das proteínas que participam do processo de fosforilação oxidativa, além de componentes de RNA (ribossômico - rRNA e transportador - tRNA) necessários para o processo de síntese protéica (Bonawitz e Shadel, 2007). O mtDNA está localizado na matriz mitocondrial associada à membrana mitocondrial interna. O mtDNA codifica no total 37 genes que estão relacionados à produção de ATP, sendo destes, 13 proteínas que codificam a CTE, 22 tRNAs e 2 rRNAs (Stevnsner, et al., 2002).

Atualmente, muitos pesquisadores aderem à teoria mitocondrial do envelhecimento, sugerindo ocorrer um ciclo vicioso de danos, onde as EROs produzidas pela mitocôndria induzem mutações ao mtDNA as quais ocasionam alterações na produção de proteínas dos complexos mitocondriais, com conseqüente deterioração da função da cadeia de transporte de elétrons, que induzem a uma elevada produção de EROs, gerando mais mutações no mtDNA, e uma produção de EROs ainda maior, repetindo-se o ciclo, o que induz à morte celular e envelhecimento do organismo (Rasmussen, et al., 2003; Dufour e Larsson, 2004; Bonawitz e Shadel, 2007). A figura 7 ilustra esse processo descrito acima, onde um ciclo oxidativo de danos mitocondriais está relacionado ao envelhecimento por induzir danos celulares irreversíveis. 


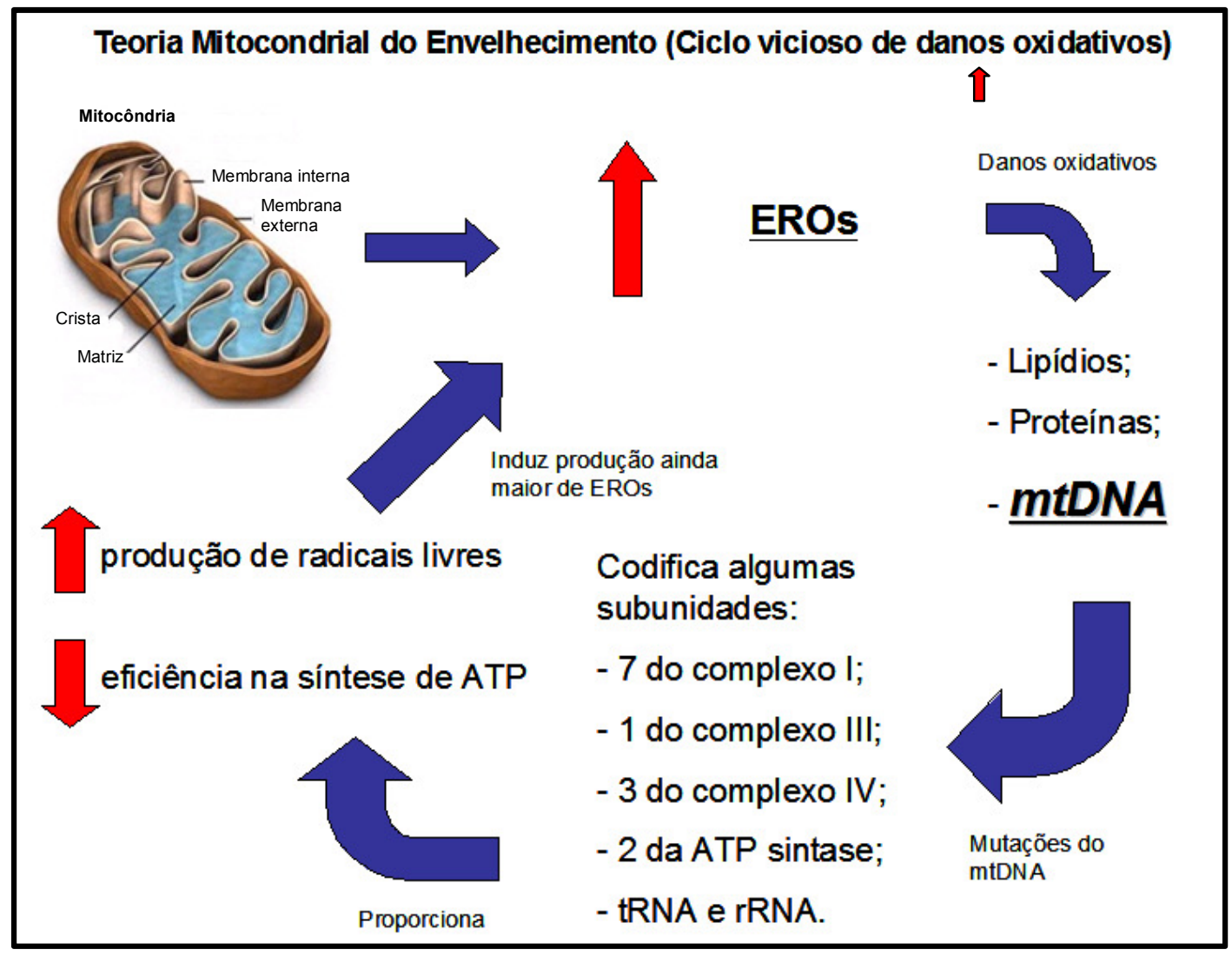

Figura 7 - Esquematização referente à teoria mitocondrial do envelhecimento. = aumento; $\mathbb{l}=$ diminuição; setas azuis = indução.

Desde sua formulação, várias evidências têm sido publicadas, dando suporte à Teoria Mitocondrial do Envelhecimento. Estudos têm demonstrado diminuição da função mitocondrial, atribuída à redução da atividade de cada um dos complexos da cadeia de transporte de elétrons (CTE) (Shigenaga, Hagen e Ames, 1994). Além disso, pesquisadores encontraram um aumento de 10 vezes no número de mutações do mtDNA em diversos tecidos de animais idosos (Vermulst, et al., 2007).

Com o envelhecimento, há um declínio considerável da função da cadeia de transporte de elétrons das fibras musculares, entre os 17 e 90 anos, que acompanhada de um acúmulo de citocromo c oxidase deficiente, ocasiona um aumento de "escape" de elétrons, e conseqüentemente na produção de EROs (Pansarasa, et al., 2002).

No envelhecimento a produção de EROs inicia-se principalmente no complexo I. Isso é esperado uma vez que esse complexo é o que tem o maior número de subunidades codificadas pelo mtDNA (sete), e de acordo com a Teoria 
Mitocondrial do Envelhecimento, o mtDNA é um alvo comum das EROs em decorrência de sua grande proximidade ao principal sítio produtor de oxidantes na célula. Além disso, o mtDNA é uma molécula de apenas $16,5 \mathrm{~kb}$ e não é protegida por histonas como o DNA nuclear. O complexo I é também especialmente sensível, pois as subunidades codificadas pelo mtDNA são essenciais para a formação de um complexo funcional (Sanz, Pamplona e Barja, 2006; Linnane, Kios e Vitetta, 2007).

De acordo com Van Remmen e Richardson (2001), a atividade dos complexos I, III e IV da CTE mitocondrial diminui com o envelhecimento, entretanto, a atividade do complexo II não sofre alteração. Isto pode estar relacionado com o fato de que o mtDNA codifica proteínas dos complexos I, III e IV, enquanto o complexo II é codificado apenas pelo nDNA (Mandavilli, Santos e Van Houten, 2002).

Os desacopladores mitocondriais (UCPs) induzem uma redução do potencial de membrana gerado pelo bombeamento de prótons por induzir um retorno destes através da membrana mitocondrial interna para a matriz mitocondrial, o que leva a uma diminuição da produção de EROs (Brand, et al., 2004). Com isso, de acordo com Brand, et al. (2004), as UCPs possuem papel essencial no controle de danos gerados pelo aumento na produção de EROs. No tecido muscular esquelético a isoforma predominante é a UCP-3 (Kerner, et al., 2001).

Com o envelhecimento ocorre uma marcante redução na expressão do mRNA das UCP-1, 2 e 3 (Iritani, et al., 2002). Quando comparado a quantidade de proteína total referente à UCP-3, ratos idosos apresentaram diminuição de $68 \%$ comparada a animais adultos (Kerner, et al., 2001). De acordo com Goglia e Skulachev (2003), as UCPs possuem funções antioxidantes por controlar a produção de EROs mitocondrial, ocasionando um efeito protetor, principalmente para o mtDNA e proteínas da matriz.

Como descrito anteriormente, além das EROs, as espécies reativas de nitrogênio, tendo o NO como principal elemento, também podem participar efetivamente no processo de danos ao tecido muscular esquelético. Na verdade, foi até proposto em 1997 uma teoria do envelhecimento desencadeada pelo NO (Mccann, 1997).

Estudos também têm demonstrado haver aumento na circulação de citocinas proinflamatórias em função da idade. Em idades superiores a 70 anos, há aumento na concentração plasmática de TNF- $\alpha$, IL-1 e IL-6, por exemplo, independente de 
qualquer doença (Cohen, et al., 1997). De acordo com Straub, et al. (2000), isso está relacionado com o aumento da concentração plasmática dos glicocorticóides e catecolaminas, bem como uma diminuição de hormônios do crescimento e sexuais que ocorrem mesmo com um envelhecimento saudável. Esses três processos agindo concomitantemente potencializam a perda de massa muscular observada nos idosos.

Interessantemente, de acordo com Toth e Tchernof (2000), no envelhecimento além de haver diminuição da massa muscular, ocorre também aumento do acúmulo de tecido adiposo em decorrência de uma diminuição da capacidade oxidativa, o que acaba por induzir redução da lipólise e da taxa metabólica, resultando em elevação da concentração plasmática de ácidos graxos. Foi demonstrado que a concentração plasmática de palmitato, por exemplo, foi $26 \%$ maior em idosos quando comparado com jovens. Esse aumento deve-se principalmente a uma redução da oxidação de gorduras em repouso, após a refeição e durante a prática de exercício físico (Sial, et al., 1996; Toth e Tchernof, 2000).

Comprovando essas evidências, em estudo realizado por Papa (1996), com mitocôndrias isoladas, foi verificado que com o envelhecimento ocorre diminuição na taxa respiratória mitocondrial, evidenciando a diminuição funcional da mitocôndria. Resultados similares foram encontrados quando utilizada a ressonância magnética nuclear para análises in vivo, demonstrando também uma menor densidade mitocondrial, capacidade oxidativa e declínio da taxa de produção de ATP com o envelhecimento (Conley, Jubrias e Esselman, 2000). Hepple, et al. (2003), demonstraram diminuição da capacidade oxidativa muscular, levando ao declínio na atividade aeróbia máxima. Esses eventos, segundo os próprios autores, relacionamse com a diminuição da atividade respiratória mitocondrial decorrida com o envelhecimento.

A beta oxidação de ácidos graxos de cadeia longa é de fundamental importância para geração de energia para o organismo, principalmente para o coração e músculo esquelético (Bartlett e Eaton, 2004). Esse processo é principalmente estimulado quando os níveis de glicose estão baixos, como no jejum ou em exercícios de endurance (Eaton, Bartlett e Pourfarzam, 1996).

$\mathrm{Na}$ verdade a mobilização de $A G$ dos estoques de TG constitui o primeiro passo para utilização deste substrato como fonte de energia pelo músculo esquelético. Estes AG devem, no entanto, ser transportados para o interior da fibra 
muscular e então para a mitocôndria para que possam ser oxidados através da beta oxidação. Até recentemente acreditava-se que os AG atravessavam a membrana das células musculares por simples difusão, entretanto, atualmente já é consensual a presença de proteínas facilitadoras que fazem o transporte de ácidos graxos para o interior das células. Uma vez no interior das células os AG são transportados para dentro das mitocôndrias através da carnitina palmitoiltranferase-I (CPT-I), enzima chave deste processo (Horowitz, 2003).

A maior parte da energia estocada no organismo humano está como triacilgliceróis (TG) nos adipócitos. A maioria dos adultos possui $>80.000 \mathrm{kcal}$ de energia estocados no tecido adiposo, a qual é suficiente para completar cerca de 25 maratonas e é mais que 40 vezes maior que o total de energia estocado em forma de glicogênio no músculo esquelético e no fígado. Visto isso, a oxidação desses TG é essencial para a manutenção de uma atividade física e pode retardar a depleção de glicogênio e a hipoglicemia (Horowitz, 2003).

Os ácidos graxos (AG) são formados por uma cadeia carbônica com um grupo carboxil em uma das terminações e um grupo metil em outra. Eles são usualmente citados por seus nomes, mas é muito mais informativa sua indicação de número de carbonos, número de duplas ligações e posições dessas duplas ligações. O ácido palmítico (palmitato), por exemplo, é descrito como 16:0, ou seja, essa conotação informa que esse AG possui dezesseis carbonos e nenhuma dupla ligação, sendo, portanto um AG saturado. Já o ácido oléico (oleato) é descrito como

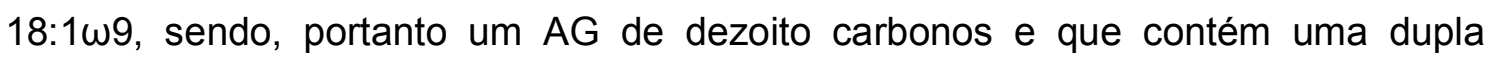
ligação ( $A G$ insaturado) sendo que a primeira encontra-se no carbono 9 a partir do grupo metil.

Com o envelhecimento há liberação de $A G$ além das necessidades metabólicas. Em estudo feito por Toth, et al. (1996), foi observado que, em condições de repouso, a taxa de liberação de AG é maior em indivíduos idosos apesar de sua menor taxa metabólica basal. Além disso, Sial, et al. (1996), demonstraram que durante exercícios de igual gasto calórico, a taxa de liberação de AG foi maior nos idosos que em indivíduos jovens.

Os mecanismos envolvidos nesse aumento na liberação de AG no processo de envelhecimento ainda não foram completamente elucidados. Apesar disso, de acordo com Bolinder, Ostman e Arner (1983), parte desse efeito deve-se a uma 
redução da sensibilidade ao efeito antilipolítico exercido pela insulina, um dos principais hormônios controladores da lipólise em humanos (Horowitz, 2003).

Com o envelhecimento há também uma redução na atividade da CPT-I. Esses dados foram encontrados no tecido muscular esquelético de ratos idosos. Há também uma redução na capacidade oxidativa do músculo de ratos idosos. Entretanto, diversos autores demonstraram atenuação ou até mesmo eliminação destas perdas após a realização de um protocolo de treinamento (Kerner, et al., 2001). Foi observado também por Kerner, et al. (2001), uma redução na quantidade total de carnitina em músculo de ratos idosos, resultado que também contribui para o comprometimento do processo de oxidação de ácidos graxos na mitocôndria.

De um modo geral, apesar de a capacidade glicolítica de indivíduos idosos permanecer normal, a atividade de enzimas envolvidas no metabolismo oxidativo (succinato desidrogenase, citrato sintase, citocromo c oxidase) é diminuída com o envelhecimento (Toth e Tchernof, 2000).

Com o envelhecimento, portanto, há aumento na produção de EROs, ERNs, citocinas, como também da concentração plasmática de ácidos graxos. No entanto, apesar dos extensivos estudos acerca do processo de envelhecimento, ainda não se sabe se existe alguma relação entre esses processos na indução da perda de massa muscular acentuada, a qual é observada no processo de envelhecimento. 


\section{CONCLUSÕES}

Os resultados obtidos no presente estudo confirmaram a hipótese inicial do trabalho: o ácido palmítico é capaz de modular diretamente a produção de espécies reativas de oxigênio e nitrogênio, bem como a de miocinas (IL-6 e CINC-2). Além disso, foi observado que a contração muscular, neste caso induzida por um protocolo de eletroestimulação de intensidade moderada, apesar de também induzir aumento da produção de espécies reativas, pode melhorar os sistemas antioxidante muscular, além de reduzir a concentração plasmática de ácidos graxos, reduzindo assim os efeitos adversos do acúmulo acentuado deste metabólito.

Com isso pode-se afirmar que no envelhecimento, os já descritos processos de diminuição do tecido muscular esquelético e aumento da concentração plasmática de ácidos graxos, tratam-se de fatores chave para a progressão da sarcopenia,e que a prática regular de atividades físicas com intensidade moderada pode trazer inúmeros benefícios, sendo importante terapia para a prevenção e/ou tratamento da sarcopenia. 


\section{REFERÊNCIAS BIBLIOGRÁFICAS}

Adams GR, Haddad F, Baldwin KM. Interaction of chronic creatine depletion and muscle unloading: effects on postural locomotor muscles. J Appl Physiol. 1994 Sep;77(3):1198-205.

Adams MR, Jessup W, Hailstones D, Celermajer DS. L-arginine reduces human monocyte adhesion to vascular endothelium and endothelial expression of cell adhesion molecules. Circulation. 1997 Feb 4;95(3):662-8.

Akerstrom T, Steensberg A, Keller P, Keller C, Penkowa M, Pedersen BK. Exercise induces interleukin-8 expression in human skeletal muscle. J Physiol. 2005 Mar 1;563(Pt 2):507-16.

Aljada A, Saadeh R, Assian E, Ghanim H, Dandona P. Insulin inhibits the expression of intercellular adhesion molecule-1 by human aortic endothelial cells through stimulation of nitric oxide. J Clin Endocrinol Metab. 2000 Jul;85(7):2572-5.

Alleva DG, Johnson EB, Lio FM, Boehme SA, Conlon PJ, Crowe PD. Regulation of murine macrophage proinflammatory and anti-inflammatory cytokines by ligands for peroxisome proliferator-activated receptor-gamma: counter-regulatory activity by IFNgamma. J Leukoc Biol. 2002 Apr;71(4):677-85.

Ashbrook JD, Spector AA, Santos EC, Fletcher JE. Long chain fatty acid binding to human plasma albumin. J Biol Chem. 1975 Mar 25;250(6):2333-8.

Balaban RS, Nemoto S, Finkel T. Mitochondria, oxidants, and aging. Cell. 2005 Feb 25;120(4):483-95.

Ballmer PE, Ochsenbein AF, Schutz-Hofmann S. Transcapillary escape rate of albumin positively correlates with plasma albumin concentration in acute but not in chronic inflammatory disease. Metabolism. 1994 Jun;43(6):697-705.

Banerjee AK, Mandal A, Chanda D, Chakraborti S. Oxidant, antioxidant and physical exercise. Mol Cell Biochem. 2003 Nov;253(1-2):307-12.

Bartlett K, Eaton S. Mitochondrial beta-oxidation. Eur J Biochem. 2004 Feb;271(3):462-9.

Bedard K, Krause KH. The NOX family of ROS-generating NADPH oxidases: physiology and pathophysiology. Physiol Rev. 2007 Jan;87(1):245-313.

Blander G, de Oliveira RM, Conboy CM, Haigis M, Guarente L. Superoxide dismutase 1 knock-down induces senescence in human fibroblasts. J Biol Chem. 2003 Oct 3;278(40):38966-9.

De acordo com:

International Comittee of Medical Journal Editors. Uniform requirements for manuscripts submitted to Biomedical Journal: sample references. C2003 - Available from: http://www.icmje.org [2007 May 22]. 
Boengler K, Gres P, Cabestrero A, Ruiz-Meana M, Garcia-Dorado D, Heusch G, Schulz R. Prevention of the ischemia-induced decrease in mitochondrial Tom20 content by ischemic preconditioning. J Mol Cell Cardiol. 2006 Sep;41(3):426-30.

Bolinder J, Ostman J, Arner $\mathrm{P}$. Influence of aging on insulin receptor binding and metabolic effects of insulin on human adipose tissue. Diabetes. 1983 Oct;32(10):95964.

Bonawitz ND, Shadel GS. Rethinking the mitochondrial theory of aging: the role of mitochondrial gene expression in lifespan determination. Cell Cycle. 2007 Jul 1;6(13):1574-8.

Borges F, Fernandes E, Roleira F. Progress towards the discovery of xanthine oxidase inhibitors. Curr Med Chem. 2002 Jan;9(2):195-217.

Bortoli S, Renault V, Eveno E, Auffray C, Butler-Browne G, Pietu G. Gene expression profiling of human satellite cells during muscular aging using cDNA arrays. Gene. 2003 Dec 4;321:145-54.

Bradford MM. A rapid and sensitive method for the quantitation of microgram quantities of protein utilizing the principle of protein-dye binding. Anal Biochem. 1976 May 7;72:248-54.

Brand MD, Affourtit C, Esteves TC, Green K, Lambert AJ, Miwa S, Pakay JL, Parker N. Mitochondrial superoxide: production, biological effects, and activation of uncoupling proteins. Free Radic Biol Med. 2004 Sep 15;37(6):755-67.

Burges RA, Butt WD, Baggaley A. Some effects of alpha-bromopalmitate, an inhibitor of fatty acid oxidation, on carbohydrate metabolism in the rat. Biochem J. 1968 Sep;109(3):38P-39P.

Carlson LA, Ekelund LG, Froberg SO. Concentration of triglycerides, phospholipids and glycogen in skeletal muscle and of free fatty acids and beta-hydroxybutyric acid in blood in man in response to exercise. Eur J Clin Invest. 1971 Jan;1(4):248-54.

Carmeli E, Moas M, Reznick AZ, Coleman R. Matrix metalloproteinases and skeletal muscle: a brief review. Muscle Nerve. 2004 Feb;29(2):191-7.

Ceddia RB, William WN, Jr., Curi R. Comparing effects of leptin and insulin on glucose metabolism in skeletal muscle: evidence for an effect of leptin on glucose uptake and decarboxylation. Int J Obes Relat Metab Disord. 1999 Jan;23(1):75-82.

Chance $B$, Sies $H$, Boveris A. Hydroperoxide metabolism in mammalian organs. Physiol Rev. 1979 Jul;59(3):527-605.

Chomczynski P, Sacchi N. Single-step method of RNA isolation by acid guanidinium thiocyanate-phenol-chloroform extraction. Anal Biochem. 1987 Apr;162(1):156-9. 
Clancy RM, Leszczynska-Piziak J, Abramson SB. Nitric oxide, an endothelial cell relaxation factor, inhibits neutrophil superoxide anion production via a direct action on the NADPH oxidase. J Clin Invest. 1992 Sep;90(3):1116-21.

Cohen HJ, Pieper CF, Harris T, Rao KM, Currie MS. The association of plasma IL-6 levels with functional disability in community-dwelling elderly. J Gerontol A Biol Sci Med Sci. 1997 Jul;52(4):M201-8.

Conley KE, Jubrias SA, Esselman PC. Oxidative capacity and ageing in human muscle. J Physiol. 2000 Jul 1;526 Pt 1:203-10.

Cornelison DD, Wold BJ. Single-cell analysis of regulatory gene expression in quiescent and activated mouse skeletal muscle satellite cells. Dev Biol. 1997 Nov 15; 191(2):270-83.

Cross AR, Jones OT. The effect of the inhibitor diphenylene iodonium on the superoxide-generating system of neutrophils. Specific labelling of a component polypeptide of the oxidase. Biochem J. 1986 Jul 1;237(1):111-6.

Dedkov El, Borisov AB, Wernig A, Carlson BM. Aging of skeletal muscle does not affect the response of satellite cells to denervation. J Histochem Cytochem. 2003 Jul;51(7):853-63.

Delp MD, Duan C. Composition and size of type I, IIA, IID/X, and IIB fibers and citrate synthase activity of rat muscle. J Appl Physiol. 1996 Jan;80(1):261-70.

Dhaunsi GS, Kaur J, Alsaeid K, Turner RB, Bitar MS. Very long chain fatty acids activate NADPH oxidase in human dermal fibroblasts. Cell Biochem Funct. 2005 JanFeb;23(1):65-8.

Di Paola M, Lorusso M. Interaction of free fatty acids with mitochondria: coupling, uncoupling and permeability transition. Biochim Biophys Acta. 2006 Sep-Oct;1757(910):1330-7.

Ding $\mathrm{AH}$, Nathan $\mathrm{CF}$, Stuehr DJ. Release of reactive nitrogen intermediates and reactive oxygen intermediates from mouse peritoneal macrophages. Comparison of activating cytokines and evidence for independent production. J Immunol. 1988 Oct 1;141(7):2407-12.

Dufour E, Larsson NG. Understanding aging: revealing order out of chaos. Biochim Biophys Acta. 2004 Jul 23;1658(1-2):122-32.

Duval C, Camara Y, Hondares E, Sibille B, Villarroya F. Overexpression of mitochondrial uncoupling protein-3 does not decrease production of the reactive oxygen species, elevated by palmitate in skeletal muscle cells. FEBS Lett. 2007 Mar 6;581(5):955-61.

Eaton S, Bartlett K, Pourfarzam M. Mammalian mitochondrial beta-oxidation. Biochem J. 1996 Dec 1;320 ( Pt 2):345-57. 
Edstrom E, Ulfhake B. Sarcopenia is not due to lack of regenerative drive in senescent skeletal muscle. Aging Cell. 2005 Apr;4(2):65-77.

Elmadhoun BM, Wang GQ, Templeton JF, Burczynski FJ. Binding of [3H]palmitate to BSA. Am J Physiol. 1998 Oct;275(4 Pt 1):G638-44.

Engel WK. Selective and nonselective susceptibility of muscle fiber types. A new approach to human neuromuscular diseases. Arch Neurol. 1970 Feb;22(2):97-117.

Espinosa A, Leiva A, Pena M, Muller M, Debandi A, Hidalgo C, Carrasco MA, Jaimovich $\mathrm{E}$. Myotube depolarization generates reactive oxygen species through $\mathrm{NAD}(\mathrm{P}) \mathrm{H}$ oxidase; ROS-elicited $\mathrm{Ca} 2+$ stimulates ERK, CREB, early genes. J Cell Physiol. 2006 Nov;209(2):379-88.

Fielding RA, Manfredi TJ, Ding W, Fiatarone MA, Evans WJ, Cannon JG. Acute phase response in exercise. III. Neutrophil and IL-1 beta accumulation in skeletal muscle. Am J Physiol. 1993 Jul;265(1 Pt 2):R166-72.

Figueiredo PA, Mota MP, Appell HJ, Duarte JA. The role of mitochondria in aging of skeletal muscle. Biogerontology. 2008 Apr;9(2):67-84.

Fink B, Laude K, McCann L, Doughan A, Harrison DG, Dikalov S. Detection of intracellular superoxide formation in endothelial cells and intact tissues using dihydroethidium and an HPLC-based assay. Am J Physiol Cell Physiol. 2004 Oct;287(4):C895-902.

Finkel T, Holbrook NJ. Oxidants, oxidative stress and the biology of ageing. Nature. 2000 Nov 9;408(6809):239-47.

Fitts $\mathrm{RH}$. Effects of regular exercise training on skeletal muscle contractile function. Am J Phys Med Rehabil. 2003 Apr;82(4):320-31.

Fulle S, Protasi F, Di Tano G, Pietrangelo T, Beltramin A, Boncompagni S, Vecchiet $\mathrm{L}$, Fano $\mathrm{G}$. The contribution of reactive oxygen species to sarcopenia and muscle ageing. Exp Gerontol. 2004 Jan;39(1):17-24.

Giulivi C, Poderoso JJ, Boveris A. Production of nitric oxide by mitochondria. J Biol Chem. 1998 May 1;273(18):11038-43.

Goglia F, Skulachev VP. A function for novel uncoupling proteins: antioxidant defense of mitochondrial matrix by translocating fatty acid peroxides from the inner to the outer membrane leaflet. Faseb J. 2003 Sep;17(12):1585-91.

Guttridge DC. Signaling pathways weigh in on decisions to make or break skeletal muscle. Curr Opin Clin Nutr Metab Care. 2004 Jul;7(4):443-50.

Haddad F, Zaldivar F, Cooper DM, Adams GR. IL-6-induced skeletal muscle atrophy. J Appl Physiol. 2005 Mar;98(3):911-7. 
Halliwell B, Gutteridge JMC. Free Radicals in Biology and Medicine. New York: Oxford University Press; 1999.

Hamilton JA, Kamp F. How are free fatty acids transported in membranes? Is it by proteins or by free diffusion through the lipids? Diabetes. 1999 Dec;48(12):2255-69.

Hardy SJ, Ferrante A, Poulos A, Robinson BS, Johnson DW, Murray AW. Effect of exogenous fatty acids with greater than 22 carbon atoms (very long chain fatty acids) on superoxide production by human neutrophils. J Immunol. 1994 Aug $15 ; 153(4): 1754-61$.

Harman D. Aging: a theory based on free radical and radiation chemistry. J Gerontol. 1956 Jul;11(3):298-300.

7. . The biologic clock: the mitochondria? J Am Geriatr Soc. 1972 Apr;20(4):145. The aging process. Proc Natl Acad Sci U S A. 1981 Nov;78(11):7124-8.

Hatanaka E, Levada-Pires AC, Pithon-Curi TC, Curi R. Systematic study on ROS production induced by oleic, linoleic, and gamma-linolenic acids in human and rat neutrophils. Free Radic Biol Med. 2006 Oct 1;41(7):1124-32.

Hellemans J, Mortier G, De Paepe A, Speleman F, Vandesompele J. qBase relative quantification framework and software for management and automated analysis of real-time quantitative PCR data. Genome Biol. 2007;8(2):R19.

Hellsten Y, Frandsen U. Adenosine formation in contracting primary rat skeletal muscle cells and endothelial cells in culture. J Physiol. 1997 Nov 1;504 (Pt 3):695704.

Hepple RT, Hagen JL, Krause DJ, Jackson CC. Aerobic power declines with aging in rat skeletal muscles perfused at matched convective $\mathrm{O} 2$ delivery. J Appl Physiol. 2003 Feb;94(2):744-51.

Higuchi R, Dollinger G, Walsh PS, Griffith R. Simultaneous amplification and detection of specific DNA sequences. Biotechnology (N Y). 1992 Apr;10(4):413-7.

Hirabara SM, Silveira LR, Alberici LC, Leandro CV, Lambertucci RH, Polimeno GC, Cury Boaventura MF, Procopio J, Vercesi AE, Curi R. Acute effect of fatty acids on metabolism and mitochondrial coupling in skeletal muscle. Biochim Biophys Acta. 2006 Jan;1757(1):57-66.

Hodgetts V, Coppack SW, Frayn KN, Hockaday TD. Factors controlling fat mobilization from human subcutaneous adipose tissue during exercise. J Appl Physiol. 1991 Aug;71(2):445-51.

Hollander J, Fiebig R, Gore M, Ookawara T, Ohno H, Ji LL. Superoxide dismutase gene expression is activated by a single bout of exercise in rat skeletal muscle. Pflugers Arch. 2001 Jun;442(3):426-34. 
Horani MH, Haas MJ, Mooradian AD. Saturated, unsaturated, and trans-fatty acids modulate oxidative burst induced by high dextrose in human umbilical vein endothelial cells. Nutrition. 2006 Feb;22(2):123-7.

Horowitz JF. Fatty acid mobilization from adipose tissue during exercise. Trends Endocrinol Metab. 2003 Oct;14(8):386-92.

Iritani N, Sugimoto T, Fukuda H, Tomoe K. Changes in UCP family expressions in rat tissues due to diet and aging. J Nutr Sci Vitaminol (Tokyo). 2002 Oct;48(5):410-6.

Jackson MJ, Pye D, Palomero J. The production of reactive oxygen and nitrogen species by skeletal muscle. J Appl Physiol. 2007 Apr;102(4):1664-70.

Jensen L, Schjerling P, Hellsten Y. Regulation of VEGF and bFGF mRNA expression and other proliferative compounds in skeletal muscle cells. Angiogenesis. 2004;7(3):255-67.

Ji LL. Oxidative stress during exercise: implication of antioxidant nutrients. Free Radic Biol Med. 1995 Jun;18(6):1079-86.

. Antioxidants and oxidative stress in exercise. Proc Soc Exp Biol Med. 1999 Dec;222(3):283-92.

Ji LL, Gomez-Cabrera MC, Steinhafel N, Vina J. Acute exercise activates nuclear factor (NF)-kappaB signaling pathway in rat skeletal muscle. Faseb J. 2004 Oct;18(13):1499-506.

Ji LL, Gomez-Cabrera MC, Vina J. Exercise and hormesis: activation of cellular antioxidant signaling pathway. Ann N Y Acad Sci. 2006 May;1067:425-35.

Ji LL, Leeuwenburgh C, Leichtweis S, Gore M, Fiebig R, Hollander J, Bejma J. Oxidative stress and aging. Role of exercise and its influences on antioxidant systems. Ann N Y Acad Sci. 1998 Nov 20;854:102-17.

Jove M, Planavila A, Laguna JC, Vazquez-Carrera M. Palmitate-induced interleukin 6 production is mediated by protein kinase $\mathrm{C}$ and nuclear-factor kappaB activation and leads to glucose transporter 4 down-regulation in skeletal muscle cells. Endocrinology. 2005 Jul;146(7):3087-95.

Kadri-Hassani N, Leger CL, Descomps B. The fatty acid bimodal action on superoxide anion production by human adherent monocytes under phorbol 12myristate 13-acetate or diacylglycerol activation can be explained by the modulation of protein kinase C and p47phox translocation. J Biol Chem. 1995 Jun 23;270(25):15111-8.

Kampf JP, Kleinfeld AM. Is membrane transport of FFA mediated by lipid, protein, or both? An unknown protein mediates free fatty acid transport across the adipocyte plasma membrane. Physiology (Bethesda). 2007 Feb;22:7-14. 
Kang D, Hamasaki N. Mitochondrial oxidative stress and mitochondrial DNA. Clin Chem Lab Med. 2003 Oct;41(10):1281-8.

Kerner J, Turkaly PJ, Minkler PE, Hoppel CL. Aging skeletal muscle mitochondria in the rat: decreased uncoupling protein-3 content. Am J Physiol Endocrinol Metab. 2001 Nov;281(5):E1054-62.

Kersten S, Desvergne B, Wahli W. Roles of PPARs in health and disease. Nature. 2000 May 25;405(6785):421-4.

Khassaf M, McArdle A, Esanu C, Vasilaki A, McArdle F, Griffiths RD, Brodie DA, Jackson MJ. Effect of vitamin $C$ supplements on antioxidant defence and stress proteins in human lymphocytes and skeletal muscle. J Physiol. 2003 Jun 1;549(Pt 2):645-52.

Kim C, Dinauer MC. Impaired NADPH oxidase activity in Rac2-deficient murine neutrophils does not result from defective translocation of p47phox and p67phox and can be rescued by exogenous arachidonic acid. J Leukoc Biol. 2006 Jan;79(1):22334.

Kojima H, Sakurai K, Kikuchi K, Kawahara S, Kirino Y, Nagoshi H, Hirata Y, Nagano T. Development of a fluorescent indicator for nitric oxide based on the fluorescein chromophore. Chem Pharm Bull (Tokyo). 1998 Feb;46(2):373-5.

Kruszynska YT, Sherratt HS. Glucose kinetics during acute and chronic treatment of rats with 2[6(4-chloro-phenoxy)hexyl]oxirane-2-carboxylate, etomoxir. Biochem Pharmacol. 1987 Nov 15;36(22):3917-21.

Kua $\mathrm{CH}$. Uncoupling the relationship between fatty acids and longevity. IUBMB Life. 2006 Mar;58(3):153-5.

Lagranha CJ, de Lima TM, Senna SM, Doi SQ, Curi R, Pithon-Curi TC. The effect of glutamine supplementation on the function of neutrophils from exercised rats. Cell Biochem Funct. 2005 Mar-Apr;23(2):101-7.

Lambertucci RH, Levada-Pires AC, Rossoni LV, Curi R, Pithon-Curi TC. Effects of aerobic exercise training on antioxidant enzyme activities and mRNA levels in soleus muscle from young and aged rats. Mech Ageing Dev. 2007 Mar;128(3):267-75.

Larson-Meyer DE, Newcomer BR, Hunter GR. Influence of endurance running and recovery diet on intramyocellular lipid content in women: a $1 \mathrm{H}$ NMR study. Am J Physiol Endocrinol Metab. 2002 Jan;282(1):E95-E106.

Leighton B, Budohoski L, Lozeman FJ, Challiss RA, Newsholme EA. The effect of prostaglandins E1, E2 and F2 alpha and indomethacin on the sensitivity of glycolysis and glycogen synthesis to insulin in stripped soleus muscles of the rat. Biochem $\mathrm{J}$. 1985 Apr 1;227(1):337-40. 
Linnane AW, Kios M, Vitetta L. Healthy aging: regulation of the metabolome by cellular redox modulation and prooxidant signaling systems: the essential roles of superoxide anion and hydrogen peroxide. Biogerontology. 2007 Oct;8(5):445-67.

Linnane AW, Marzuki S, Ozawa T, Tanaka M. Mitochondrial DNA mutations as an important contributor to ageing and degenerative diseases. Lancet. 1989 Mar $25 ; 1(8639): 642-5$.

Liu H, Zhang D, Zhao B, Zhao J. Superoxide anion, the main species of ROS in the development of ARDS induced by oleic acid. Free Radic Res. 2004 Dec;38(12):1281-7.

Lledias F, Rangel P, Hansberg W. Oxidation of catalase by singlet oxygen. J Biol Chem. 1998 Apr 24;273(17):10630-7.

Lopez-Soriano J, Chiellini C, Maffei M, Grimaldi PA, Argiles JM. Roles of skeletal muscle and peroxisome proliferator-activated receptors in the development and treatment of obesity. Endocr Rev. 2006 May;27(3):318-29.

Mandavilli BS, Santos JH, Van Houten B. Mitochondrial DNA repair and aging. Mutat Res. 2002 Nov 30;509(1-2):127-51.

Mansouri A, Muller FL, Liu Y, Ng R, Faulkner J, Hamilton M, Richardson A, Huang TT, Epstein CJ, Van Remmen $\mathrm{H}$. Alterations in mitochondrial function, hydrogen peroxide release and oxidative damage in mouse hind-limb skeletal muscle during aging. Mech Ageing Dev. 2006 Mar;127(3):298-306.

Marletta MA, Hurshman AR, Rusche KM. Catalysis by nitric oxide synthase. Curr Opin Chem Biol. 1998 Oct;2(5):656-63.

Martins de Lima T, Gorjao R, Hatanaka E, Cury-Boaventura MF, Portioli Silva EP, Procopio J, Curi R. Mechanisms by which fatty acids regulate leucocyte function. Clin Sci (Lond). 2007 Jul;113(2):65-77.

Maziere C, Conte MA, Degonville J, Ali D, Maziere JC. Cellular enrichment with polyunsaturated fatty acids induces an oxidative stress and activates the transcription factors AP1 and NFkappaB. Biochem Biophys Res Commun. 1999 Nov;265(1):11622.

McArdle A, Vasilaki A, Jackson M. Exercise and skeletal muscle ageing: cellular and molecular mechanisms. Ageing Res Rev. 2002 Feb;1(1):79-93.

McCann SM. The nitric oxide hypothesis of brain aging. Exp Gerontol. 1997 JulOct;32(4-5):431-40.

McCann SM, Mastronardi C, de Laurentiis A, Rettori V. The nitric oxide theory of aging revisited. Ann N Y Acad Sci. 2005 Dec;1057:64-84.

McCord JM. Free radicals and inflammation: protection of synovial fluid by superoxide dismutase. Science. 1974 Aug 9;185(150):529-31. 
McCord JM, Fridovich I. The reduction of cytochrome c by milk xanthine oxidase. J Biol Chem. 1968 Nov 10;243(21):5753-60.

. Superoxide dismutase. An enzymic function for erythrocuprein (hemocuprein). J Biol Chem. 1969 Nov 25;244(22):6049-55.

Medvedev ZA. An attempt at a rational classification of theories of ageing. Biol Rev Camb Philos Soc. 1990 Aug;65(3):375-98.

Miquel J. An integrated theory of aging as the result of mitochondrial-DNA mutation in differentiated cells. Arch Gerontol Geriatr. 1991 Mar-Jun;12(2-3):99-117.

Miquel J, Economos AC, Fleming J, Johnson JE, Jr. Mitochondrial role in cell aging. Exp Gerontol. 1980;15(6):575-91.

Miwa S, Brand MD. Mitochondrial matrix reactive oxygen species production is very sensitive to mild uncoupling. Biochem Soc Trans. 2003 Dec;31(Pt 6):1300-1.

Miyasaka CK, Mendonca JR, Nishiyama A, de Souza JA, Pires de Melo M, PithonCuri TC, Curi R. Comparative effects of fish oil given by gavage and fish oil-enriched diet on leukocytes. Life Sci. 2001 Aug 31;69(15):1739-51.

Morio B, Hocquette JF, Montaurier C, Boirie Y, Bouteloup-Demange C, McCormack C, Fellmann N, Beaufrere B, Ritz $P$. Muscle fatty acid oxidative capacity is a determinant of whole body fat oxidation in elderly people. Am J Physiol Endocrinol Metab. 2001 Jan;280(1):E143-9.

Muller FL, Liu Y, Van Remmen H. Complex III releases superoxide to both sides of the inner mitochondrial membrane. J Biol Chem. 2004 Nov 19;279(47):49064-73.

Nakagawa H, Komorita N, Shibata F, Ikesue A, Konishi K, Fujioka M, Kato H. Identification of cytokine-induced neutrophil chemoattractants (CINC), rat GRO/CINC-2 alpha and CINC-2 beta, produced by granulation tissue in culture: purification, complete amino acid sequences and characterization. Biochem J. 1994 Jul 15;301 ( Pt 2):545-50.

Navarro A, Sanchez Del Pino MJ, Gomez C, Peralta JL, Boveris A. Behavioral dysfunction, brain oxidative stress, and impaired mitochondrial electron transfer in aging mice. Am J Physiol Regul Integr Comp Physiol. 2002 Apr;282(4):R985-92.

Nguyen HX, Tidball JG. Interactions between neutrophils and macrophages promote macrophage killing of rat muscle cells in vitro. J Physiol. 2003 Feb 15;547(Pt 1):12532.

Ostrowski K, Schjerling P, Pedersen BK. Physical activity and plasma interleukin-6 in humans--effect of intensity of exercise. Eur J Appl Physiol. 2000 Dec;83(6):512-5.

Pahl HL. Activators and target genes of Rel/NF-kappaB transcription factors. Oncogene. 1999 Nov 22;18(49):6853-66. 
Pamplona R, Barja G, Portero-Otin M. Membrane fatty acid unsaturation, protection against oxidative stress, and maximum life span: a homeoviscous-longevity adaptation? Ann N Y Acad Sci. 2002 Apr;959:475-90.

Pansarasa O, Felzani G, Vecchiet J, Marzatico F. Antioxidant pathways in human aged skeletal muscle: relationship with the distribution of type II fibers. Exp Gerontol. 2002 Aug-Sep;37(8-9):1069-75.

Papa S. Mitochondrial oxidative phosphorylation changes in the life span. Molecular aspects and physiopathological implications. Biochim Biophys Acta. 1996 Sep 12;1276(2):87-105.

Pattwell DM, McArdle A, Morgan JE, Patridge TA, Jackson MJ. Release of reactive oxygen and nitrogen species from contracting skeletal muscle cells. Free Radic Biol Med. 2004 Oct 1;37(7):1064-72.

Patwell DM, McArdle A, Morgan JE, Patridge TA, Jackson MJ. Release of reactive oxygen and nitrogen species from contracting skeletal muscle cells. Free Radic Biol Med. 2004 Oct 1;37(7):1064-72.

Pedersen BK. IL-6 signalling in exercise and disease. Biochem Soc Trans. 2007 Nov;35(Pt 5):1295-7.

Pedersen BK, Akerstrom TC, Nielsen AR, Fischer CP. Role of myokines in exercise and metabolism. J Appl Physiol. 2007 Sep;103(3):1093-8.

Pedersen BK, Steensberg A, Schjerling P. Muscle-derived interleukin-6: possible biological effects. J Physiol. 2001 Oct 15;536(Pt 2):329-37.

Pithon-Curi TC, Levada AC, Lopes LR, Doi SQ, Curi R. Glutamine plays a role in superoxide production and the expression of p47phox, p22phox and gp91phox in rat neutrophils. Clin Sci (Lond). 2002 Oct;103(4):403-8.

Ponsot E, Zoll J, N'Guessan B, Ribera F, Lampert E, Richard R, Veksler V, VenturaClapier R, Mettauer B. Mitochondrial tissue specificity of substrates utilization in rat cardiac and skeletal muscles. J Cell Physiol. 2005 Jun;203(3):479-86.

Potter VR, Reif AE. Inhibition of an electron transport component by antimycin $\mathrm{A}$. J Biol Chem. 1952 Jan;194(1):287-97.

Rachek LI, Musiyenko SI, LeDoux SP, Wilson GL. Palmitate induced mitochondrial deoxyribonucleic acid damage and apoptosis in 16 rat skeletal muscle cells. Endocrinology. 2007 Jan;148(1):293-9.

Rasmussen UF, Krustrup P, Kjaer M, Rasmussen HN. Experimental evidence against the mitochondrial theory of aging. A study of isolated human skeletal muscle mitochondria. Exp Gerontol. 2003 Aug;38(8):877-86. 
Rattan SI. Theories of biological aging: genes, proteins, and free radicals. Free Radic Res. 2006 Dec;40(12):1230-8.

Reddy RC, Keshamouni VG, Jaigirdar SH, Zeng X, Leff T, Thannickal VJ, Standiford TJ. Deactivation of murine alveolar macrophages by peroxisome proliferatoractivated receptor-gamma ligands. Am J Physiol Lung Cell Mol Physiol. 2004 Mar;286(3):L613-9.

Reid MB, Durham WJ. Generation of reactive oxygen and nitrogen species in contracting skeletal muscle: potential impact on aging. Ann N Y Acad Sci. 2002 Apr;959:108-16.

Renault V, Thornell LE, Butler-Browne G, Mouly V. Human skeletal muscle satellite cells: aging, oxidative stress and the mitotic clock. Exp Gerontol. 2002 OctNov;37(10-11):1229-36.

Richieri GV, Kleinfeld AM. Unbound free fatty acid levels in human serum. J Lipid Res. 1995 Feb;36(2):229-40.

Rodriguez C, Mayo JC, Sainz RM, Antolin I, Herrera F, Martin V, Reiter RJ. Regulation of antioxidant enzymes: a significant role for melatonin. J Pineal Res. 2004 Jan;36(1):1-9.

Roepstorff C, Steffensen CH, Madsen M, Stallknecht B, Kanstrup IL, Richter EA, Kiens B. Gender differences in substrate utilization during submaximal exercise in endurance-trained subjects. Am J Physiol Endocrinol Metab. 2002 Feb;282(2):E43547.

Roubenoff R, Hughes VA. Sarcopenia: current concepts. J Gerontol A Biol Sci Med Sci. 2000 Dec;55(12):M716-24.

Rubanyi GM, Ho EH, Cantor EH, Lumma WC, Botelho LH. Cytoprotective function of nitric oxide: inactivation of superoxide radicals produced by human leukocytes. Biochem Biophys Res Commun. 1991 Dec 31;181(3):1392-7.

Sabourin LA, Rudnicki MA. The molecular regulation of myogenesis. Clin Genet. 2000 Jan;57(1):16-25.

Sanz A, Pamplona R, Barja G. Is the mitochondrial free radical theory of aging intact? Antioxid Redox Signal. 2006 Mar-Apr;8(3-4):582-99.

Serra V, von Zglinicki T, Lorenz M, Saretzki G. Extracellular superoxide dismutase is a major antioxidant in human fibroblasts and slows telomere shortening. J Biol Chem. 2003 Feb 28;278(9):6824-30.

Shefer G, Van de Mark DP, Richardson JB, Yablonka-Reuveni Z. Satellite-cell pool size does matter: defining the myogenic potency of aging skeletal muscle. Dev Biol. 2006 Jun 1;294(1):50-66. 
Shigenaga MK, Hagen TM, Ames BN. Oxidative damage and mitochondrial decay in aging. Proc Natl Acad Sci U S A. 1994 Nov 8;91(23):10771-8.

Sial S, Coggan AR, Carroll R, Goodwin J, Klein S. Fat and carbohydrate metabolism during exercise in elderly and young subjects. Am J Physiol. 1996 Dec;271(6 Pt 1):E983-9.

Sial S, Coggan AR, Hickner RC, Klein S. Training-induced alterations in fat and carbohydrate metabolism during exercise in elderly subjects. Am J Physiol. 1998 May;274(5 Pt 1):E785-90.

Silveira LR, Pilegaard H, Kusuhara K, Curi R, Hellsten Y. The contraction induced increase in gene expression of peroxisome proliferator-activated receptor (PPAR)gamma coactivator 1alpha (PGC-1alpha), mitochondrial uncoupling protein 3 (UCP3) and hexokinase II (HKII) in primary rat skeletal muscle cells is dependent on reactive oxygen species. Biochim Biophys Acta. 2006 Sep;1763(9):969-76.

Skulachev VP. Uncoupling: new approaches to an old problem of bioenergetics. Biochim Biophys Acta. 1998 Feb 25;1363(2):100-24.

Solfrizzi V, D'Introno A, Colacicco AM, Capurso C, Palasciano R, Capurso S, Torres F, Capurso A, Panza F. Unsaturated fatty acids intake and all-causes mortality: a 8.5year follow-up of the Italian Longitudinal Study on Aging. Exp Gerontol. 2005 Apr;40(4):335-43.

Solomon AM, Bouloux PM. Modifying muscle mass - the endocrine perspective. J Endocrinol. 2006 Nov;191(2):349-60.

Srivastava S, Chan C. Hydrogen peroxide and hydroxyl radicals mediate palmitateinduced cytotoxicity to hepatoma cells: relation to mitochondrial permeability transition. Free Radic Res. 2007 Jan;41(1):38-49.

Starkie R, Ostrowski SR, Jauffred S, Febbraio M, Pedersen BK. Exercise and IL-6 infusion inhibit endotoxin-induced TNF-alpha production in humans. Faseb J. 2003 May;17(8):884-6.

Steinberg H. Regulation of lipid and lipoprotein metabolism. In: Best and Taylor's Physiological Basis of Medical Practice. Baltimore: Williams \& Wilkins; 1985.

Stevnsner T, Thorslund T, de Souza-Pinto NC, Bohr VA. Mitochondrial repair of 8oxoguanine and changes with aging. Exp Gerontol. 2002 Oct-Nov;37(10-11):118996.

Story DA, Morimatsu H, Egi M, Bellomo R. The effect of albumin concentration on plasma sodium and chloride measurements in critically ill patients. Anesth Analg. 2007 Apr;104(4):893-7.

Straub RH, Miller LE, Scholmerich J, Zietz B. Cytokines and hormones as possible links between endocrinosenescence and immunosenescence. J Neuroimmunol. 2000 Sep 1;109(1):10-5. 
Thomas DR. Weight loss in older adults. Rev Endocr Metab Disord. 2005 May;6(2):129-36.

. Loss of skeletal muscle mass in aging: examining the relationship of starvation, sarcopenia and cachexia. Clin Nutr. 2007 Aug;26(4):389-99.

Tidball JG. Inflammatory processes in muscle injury and repair. Am J Physiol Regul Integr Comp Physiol. 2005 Feb;288(2):R345-53.

Toth MJ, Arciero PJ, Gardner AW, Calles-Escandon J, Poehlman ET. Rates of free fatty acid appearance and fat oxidation in healthy younger and older men. $\mathrm{J} A p p l$ Physiol. 1996 Feb;80(2):506-11.

Toth MJ, Tchernof A. Lipid metabolism in the elderly. Eur J Clin Nutr. 2000 Jun;54 Suppl 3:S121-5.

Towbin $\mathrm{H}$, Staehelin $\mathrm{T}$, Gordon J. Electrophoretic transfer of proteins from polyacrylamide gels to nitrocellulose sheets: procedure and some applications. Proc Natl Acad Sci U S A. 1979 Sep;76(9):4350-4.

Van Remmen H, Richardson A. Oxidative damage to mitochondria and aging. Exp Gerontol. 2001 Jul;36(7):957-68.

Vandesompele J, De Preter K, Pattyn F, Poppe B, Van Roy N, De Paepe A, Speleman F. Accurate normalization of real-time quantitative RT-PCR data by geometric averaging of multiple internal control genes. Genome Biol. 2002 Jun 18;3(7):RESEARCH0034.

Vassilakopoulos T, Govindaraju K, Parthenis D, Eidelman DH, Watanabe Y, Hussain SN. Nitric oxide production in the ventilatory muscles in response to acute resistive loading. Am J Physiol Lung Cell Mol Physiol. 2007 Apr;292(4):L1013-22.

Vermulst M, Bielas JH, Kujoth GC, Ladiges WC, Rabinovitch PS, Prolla TA, Loeb LA. Mitochondrial point mutations do not limit the natural lifespan of mice. Nat Genet. 2007 Apr;39(4):540-3.

Visser M, Pahor M, Taaffe DR, Goodpaster BH, Simonsick EM, Newman AB, Nevitt M, Harris TB. Relationship of interleukin-6 and tumor necrosis factor-alpha with muscle mass and muscle strength in elderly men and women: the Health ABC Study. J Gerontol A Biol Sci Med Sci. 2002 May;57(5):M326-32.

Watt MJ, Heigenhauser GJ, Spriet LL. Effects of dynamic exercise intensity on the activation of hormone-sensitive lipase in human skeletal muscle. J Physiol. 2003 Feb 15;547(Pt 1):301-8.

Wei Y, Chen K, Whaley-Connell AT, Stump CS, Ibdah JA, Sowers JR. Skeletal muscle insulin resistance: role of inflammatory cytokines and reactive oxygen species. Am J Physiol Regul Integr Comp Physiol. 2008 Mar;294(3):R673-80. 
Wei YH, Lee HC. Oxidative stress, mitochondrial DNA mutation, and impairment of antioxidant enzymes in aging. Exp Biol Med (Maywood). 2002 Oct;227(9):671-82.

Wenzel U, Nickel A, Daniel H. Increased mitochondrial palmitoylcarnitine/carnitine countertransport by flavone causes oxidative stress and apoptosis in colon cancer cells. Cell Mol Life Sci. 2005 Dec;62(24):3100-5.

Wojtaszewski JF, Hansen BF, Urso B, Richter EA. Wortmannin inhibits both insulinand contraction-stimulated glucose uptake and transport in rat skeletal muscle. $J$ Appl Physiol. 1996 Oct;81(4):1501-9.

Yablonka-Reuveni Z, Day K, Vine A, Shefer G. Defining the transcriptional signature of skeletal muscle stem cells. J Anim Sci. 2008 Apr;86(14 Suppl):E207-16.

Zhou LZ, Johnson AP, Rando TA. NF kappa B and AP-1 mediate transcriptional responses to oxidative stress in skeletal muscle cells. Free Radic Biol Med. 2001 Dec 1;31(11):1405-16. 